\title{
“DO DIÁRIO EM PARIS” E “DO DIÁRIO EM PARIS-III”, DE GUIMARÃES ROSA: A LÍNGUA FRANCESA EM IMAGENS POÉTICAS.
}

\author{
Fabrício Lemos da COSTA \\ Sílvio Augusto de Oliveira HOLANDA
}

\begin{abstract}
RESUMO
Este artigo tem como objetivo refletir sobre a presença da língua francesa em "Do Diário em Paris" e "Do Diário em Paris-III", narrativas do livro Ave, Palavra, do escritor João Guimarães Rosa, publicado pela primeira vez em 1970. Para isso, abordaremos a língua francesa sob a perspectiva das imagens poéticas ao longo do texto, cujas construções colocam-se entre o cotidiano de Paris e as metáforas do "lieu". Assim, nossa reflexão dar-se-á em torno das metáforas, tal como aparecem na narrativa roseana, desenvolvendo-se em breves frases, assim como no poema final, elaborado em francês, dividido em cinco estrofes, totalizando dezoito versos. Nesse sentido, propomos uma leitura do "diário" a partir de suas construções poéticas, as quais nascem do cotidiano da cidade, demarcadas em nomes de ruas, estações de trem, paisagens e relações sociais.
\end{abstract}

Palavras-chave: Guimarães Rosa; Ave, Palavra; Do Diário em Paris; Do Diário em Paris-III; Língua Francesa.

\section{“DO DIÁRIO EM PARIS" ET “DO DIÁRIO EM PARIS-III", DE GUIMARÃES ROSA: LES IMAGES POÉTIQUES DANS LA LANGUE FRANÇAISE}

\section{RÉSUMÉ}

Cet article nous permet de nous interroger sur la présence de la langue française dans le "Do Diário em Paris" et "Do Diário em Paris-III", récits du livre Ave, Palavra, de l'auteur Guimarães Rosa, publié pour la première fois en 1970. Tout au long du texte, nous étudierons la langue française à travers l'usage de l'image poétique, dont les constructions nous imergent dans le quotidien de Paris et ses métaphores de lieu. Nous articulerons ensuite notre réflexion autour des méthaphores rencontrées dans le récit de Guimarães Rosa, développé a partir de courtes phrases, comme par exemple dans le dernier poème écrit en français et divisé en cinq strophes por un total de diz-huit vers. Dans ce contexte, nous proposerons une lecture du texte ayant pour origine ses constructions poétiques, lesquelles sursissent du quotidien de la ville, au detour des rues, gares, paysages et relations sociales.

Mots-Clés: Guimarães Rosa; "Ave, Palavra”; "Do Diário em Paris"; "Do Diário em Paris-III”; Langue Française.

\section{OF GUIMARÃES ROSA'S “DIÁRIO EM PARIS” AND "DIÁRIO EM PARIS-III": THE FRENCH LANGUAGE IN POETIC IMAGES}

\section{ABSTRACT}

This article aims at reflecting upon the presence of French language in João Guimarães Rosa's narratives entitled "Do Diário em Paris" and "Do Diário em Paris-III", from his book, Ave, Palavra, published for the first time in 1970. Thus, the French language will be approached from the poetic images in the text, whose constructions are built amidst Paris daily life and the "lieu" metaphors. Therefore, the present reflection happens within these metaphors as they appear in Rosa's narrative, developing into short sentences as in the final poem, written in French, divided in five strophes, in a total of eighteen verses. Thusly, the work is highly recommended from its poetic keys, which happen in the city's daily routine, branded on street's names, train stations, landscapes and social relations.

Keywords: Guimarães Rosa, Ave, Palavra, "Do Diário em Paris", "Do Diário em Paris-III”, French Language.

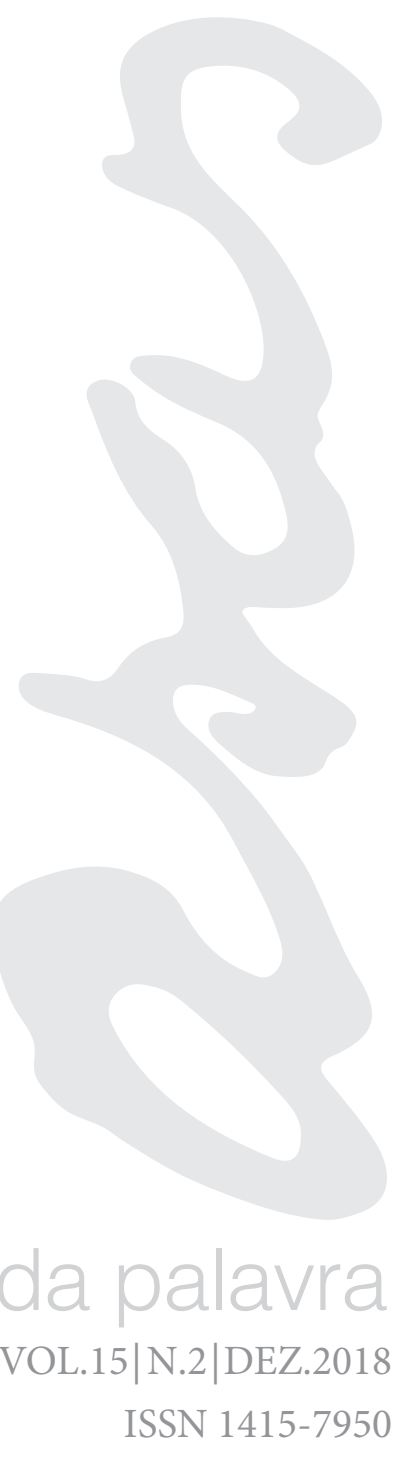




\title{
AVE, PALAVRA: UMA INTRODUÇÃO
}

\author{
"La métaphore a un pied dans chaque domaine."
}

Paul Ricœur

1 Cf. Coutinho, 2013, p. 50: “Ave, Palavra é a reunião de 55 textos literários definidos pelo autor como miscelânea. São poesias, máximas, notas de viagem e fragmentos de um diário, a maioria deles publicados em jornais e periódicos brasileiros no período de 1947 a 1967 . O livro inclui ainda cinco ensaios curtos, acrescentados no final pelo editor, que estavam destinados a integrar um volume à parte, com o título de 'Jardins e Riachinhos'."

2 As funções diplomáticas de Guimarães Rosa, assim como sua disciplina em anotar tudo que se via, fizeram-no um autor/ acumulador de paisagens e acontecimentos, os quais se desenvolviam, futuramente, em "estorias".Cf. de que Guimarães Rosa vinha se ocupando desde a infância- seja
pela curiosidade natural, seja pela curiosidade natural, seja suas fontes, seja pela exigência de suas funções diplomáticas, ou pelo exercício de aprimorar seus instrumentos estéticos- permeiam uma obstinada vontade de aprender, renovar a si mesmo e ao mundo, além do empenho quase oracular em inventariar material para uma virtual utilização futura."

3 Cf. Coutinho, 2013, p.23: "Os procedimentos empregados por Guimarães Rosa para revitalizar a linguagem narrativa são muitos e variados e se estendem do plano da língua stricto sensu ao discurso narrativo."

\author{
Ah, parmi ces durs rêves \\ J'aimerais aimer. \\ Guimarães Rosa
}

Ave, Palavra $^{1}$, de João Guimarães Rosa, foi publicado pela primeira vez em 1970, pela editora José Olympio, organizado por Paulo Rónai. É considerada uma obra póstuma do autor mineiro, constituindo-se de cinquenta e quatro narrativas, elaboradas em variados temas, como textos de caráter filosófico, registros de viagens ${ }^{2}$, espécies de "diários", crônicas circunstanciais e descrições poéticas de paisagens e momentos. A obra, caracteriza-se como uma miscelânea, cujos textos, em sua maioria, são frutos de contribuições em jornais, de maneira descontínua e esporádica. Ave, Palavra, carrega seu sentido e valor no conjunto na obra do autor de Cordisburgo, isto é, a saudação à palavra, à invenção e à experimentação da linguagem, elementos tão notáveis na ficção de Rosa. Eduardo F. Coutinho em Grande Sertão: Veredas. Travessias, ressalta:

O segundo livro [Ave, Palavra] reúne 37 textos, por ele considerados definitivos, sobre assuntos variados (notas de viagem, diários, poesias, contos, flagrantes, reportagens poéticas e meditações) publicados também na imprensa, no periodo de 1947 a 1967, além de outros trezes em que ele começara a trabalhar para esse volume, quatro dos quais inéditos. Foram acrescentadas ainda cinco crônicas, quatro das quais já publicadas, que fariam parte de outro pequeno livro, Jardins e Riachinhos. (COUTINHO, 2013, p. 16-17)

Ave, Palavra incorpora a experimentação ${ }^{3}$ da linguagem em sua relação com o cotidiano, em breves flagrantes da vida, as quais são visualizadas pelo autor, e devolvidas em imagens poéticas. A palavra dá-se em ligação com a poesia, é onde "jorra" as imagens circunstanciais e episódios da própria vivência de Guimarães Rosa no Brasil e no exterior, como é possível verificar no seguinte trecho: "Em compensação, hoje às 8 e 45, na Gare de 4 Todas as citações de "Do Diário l'Est, onde fui esperar amigos vindos do Expresso-do-Oriente, vi chegar uma em Paris" se referem a essa edição $\left(6^{a}\right.$ ed.) e serão indicadas pela abreviatura DDEP, seguida do número da página.

mulher, bonita como ninguém nunca viu" (DDEP, p. 117) ${ }^{4}$. Atentemos para outro fragmento: "28-VIII-49-Vim até ao fim da linha 9 do metrô, à Mairie de Montreuil” (DDEP-III, p. 336)

Em Ave, Palavra, é possível perceber as experiências do autor

5 Todas as citações de "Do Diário em Paris-III" se referem a essa edição ( $6^{\mathrm{a}}$ ed.) e serão indicadas pela abreviatura DDEP-III, seguida do número da página.

6 Após essa citação de "Do Diário de Paris" no corpo do texto, utilizaremos a abreviatura DDEP.

7 Após essa citação de "Do Diário de Paris- III" no corpo do texto, utilizaremos a abreviatura DDEPIII.

no exterior. Guimarães Rosa, diplomata pelo Itamaraty, transportou suas impressões e reflexões a partir de relações em escritura diplomática com outras culturas e línguas, como é o caso da língua francesa em textos que serão objetos de análise nesse estudo: Do Diário de Paris ${ }^{6}$ e Do Diário de

Paris-III ${ }^{7}$. Os "diários" são constructos de passagens por Paris, em referência à restaurantes, metrôs, nomes de ruas, assim como em anúncios, revestindo-se de imagens representativas da poiesis, isto é, da produção de uma realidade mais poética, nascidas da vida comum parisiense, como fez Charles Baudelaire. Segundo Walter Benjamin: "Com Baudelaire, pela primeira vez, Paris torna-se objeto de poesia lírica. Esta poesia não é uma arte local, mas, ante o olhar do alegorista que toca a cidade, o olhar do estranho" (BENJAMIN, 2002, p. 699). 


\section{DIÁRIOS EM PARIS: LÍNGUA FRANCESA, “LIEU” DO COTIDIANO E DA DIPLOMACIA:}

DDEP e DDEP-III desenvolvem-se em uma espécie de diplomacia entre línguas, lugar onde convive a língua portuguesa, em maior parte, a língua francesa e breves palavras em grego moderno. A língua francesa nos diários mencionados, aparece em variados tipos de discursos, como em informações de ruas, poemas e anúncios, por exemplo. Vejamos um trecho que demonstra o francês em situação cotidiana: "Todo mundo se evade. Lucy partiu de avião para o Brasil, levando na lapela um cyclamen des bois" (DDEP, p. 117). Como vemos, o discurso emerge da necessidade pragmática de mencionar um fato real em anotação de diário, mas a partir da imagem, cria-se também qualquer possibilidade de pensar o poético, em que a realidade comum, carregar um "cyclamen des bois", excita em nosso pensamento, fazendo-nos aguçar, inclusive, a curiosidade daquele fato, o motivo e suas relações com situações anteriores, por exemplo. Verifiquemos outro trecho:

\begin{abstract}
S.D. explica-me suas cores, as que devem esperar na paleta: preto (noir d'ivoire), branco (blanc d'argent), vermelho de Veneza ou ocre rubro; ocre amarelo-de-cádmio, médio. Para a paisagem as mesmas, mais: azul de cobalto e terra de Siena.

Novas, sim, são as que a moda acende e que se impõe nos figurinos: azul-vitral, azul-andorinha, verde-cacto, azul François Ier., rouge vin d'Arbois, gris nuage, violet Monsignor, miel blond. (DDEP, $p$. 118).
\end{abstract}

O fragmento acima demonstra como o uso da língua nasce do cotidiano ou de qualquer impressão do autor em relação à paisagem, bem como revela a necessidade do uso de tais imagens em francês, como nos fragmentos "noir d'ivoire", "blanc d'argent", "rouge vin d'Arbois", "violet Monsignor" e "miel blond". Além disso, arriscamo-nos a dizer que o discurso está ligado ao lugar, as cores que só podem ser transmitidas em sua língua original, não sendo possível, pois, transferir para sistemas semióticos em língua portuguesa, já que se trata de impressões cotidianas, ou seja, cores da paleta que serviriam para pintar ou capturar o "lieu" no interior da complexidade natural de Paris, como fica claro na ligação da cor e o objeto que a define. O diário de Guimarães Rosa é costurado na diplomacia, é o olhar do autor diplomático sob a cultura alheia, que ao exemplificar as cores em sua identidade semiótica, revela-se um absoluto espectador daquilo que se deve contemplar e expressar em poesia. Guimarães Rosa, em Paris, lembra-nos um atento poeta lírico na capital do capitalismo, como elabora Walter Benjamin em relação a Charles Baudelaire:

\begin{abstract}
Uma embriaguez acomete aquele que longamente vagou sem rumo pelas ruas. A cada passo, o andar ganha uma potência crescente; sempre menor se torna a sedução das lojas, dos bistrôs, das mulheres sorridentes e sempre mais irresistivel o magnetismo da próxima esquina, de uma massa de folhas distantes, de um nome de rua. (BENJAMIN, 1989, p. 186)
\end{abstract}

\section{PARIS EM ANÚNCIO: METÁFORA E COTIDIANO:}

Guimarães Rosa, nesse sentido, redimensiona o cotidiano para o diário, aliás comum em escrita que se pretende capturar a experiência do dia a dia, como um passeio em metrô parisiense. O autor mineiro, acostumado em capturar imagens dos gerais, "apanha" o poético em anúncios que se metaforizam e identificam a cidade no movimento do discurso pragmático da publicidade. Eis o anúncio: "le / rouge baiser / permet / le baiser..."
8 Cf. Coutinho, 2013, p. 22: Rosa definiu como uma de suas principais metas a tarefa de revitalizar a linguagem com o fim de fazê-la recobrar sua poiesis originária e atingir o leitor, introduzindo-o à reflexão"

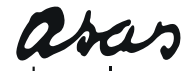

da palavra 
(DDEP, p. 119). O texto detectado pelas lentes do artista não poderia passar despercebida, passa-se, imediatamente, pelo filtro da poesia ${ }^{8}$, onde a metáfora começa: “_No metrô, em vermelho, este anúncio, que é Paris e é um poema." (DDEP, p. 119). Vejamos o anúncio:

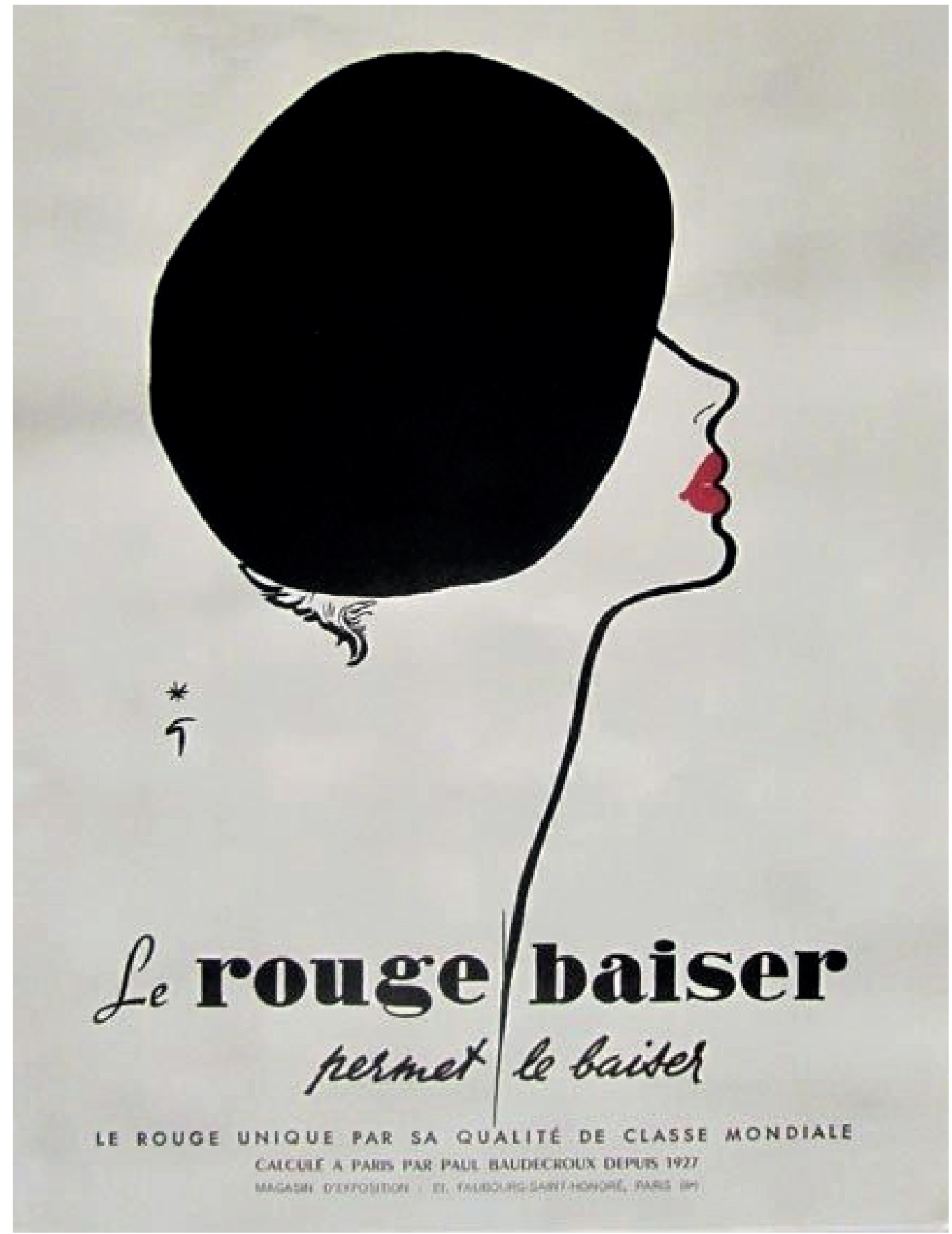

Figura 1: Original "Le rouge baiser", de Rene Gruau (1949). Disponível em: https://vepca.wordpress.com/tag/perfume/. Acesso em: 17 de setembro de 2018

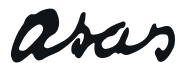
da palavra VOL. $15 \mid$ N.2 | DEZ. 2018 é superficial, mesmo carregando suas intersecções com o cotidiano e sua ISSN 1415-7950
$\mathrm{O}$ anúncio, como anuncia Rosa, é um poema, porque transborda e revela a cidade, num estado que se dá em contato com suas formas, movimentos e relações: "la lumière de la ville". A metáfora, por ora, desenvolve-se em estranhamento, pois emerge do pragmático, em discurso pronto e que se renova em dados novos, em metáfora que salta diante dos olhos, num "lampejo" de demonstração elegante, isto é, daquilo que se vê no objeto, assim como não 
repetição diante da publicidade, a qual é resgatada pelo autor/poeta como novidade, é o "arrancar as coisas de seu contexto habitual- normal com as mercadorias no estádio de sua exibição” (BENJAMIN, 1989, p. 163). Aristóteles sublinha em Retórica:

\begin{abstract}
Por outro, às palavras, se formarem uma metáfora, conquanto esta não seja estranha (pois seria de difícil compreensão), nem superficial (pois não produz nenhuma impressão); finalmente, se ela fizer que o objeto salte 'diante dos olhos'. Convém, pois, visualizar as coisas mais na sua realização do que na perspectiva de virem a realizar-se. (RETÓRICA, III, 10, 1410 b)
\end{abstract}

Nesse sentido, Paris é um poema, colocando-se em anúncio, perfazse em metáforas que são despertadas da cabeça atenta do artista, ocorrendo do discurso e em movimento que se faz em "traços" originais, longe, portanto, do simplesmente banal e comum, como fica evidente no trecho seguinte: "Que nunca sejam triviais" para mim os castanheiros." (DDEP, p. 119). Tal procedimento é comum no poeta Charles Baudelaire, "Pertence à destruição dos contextos orgânicos na intenção alegórica" (BENJAMIN, 1989, p. 163). Paris, desse modo, é o lugar da tensão, ambiente da "enganadora transfiguração do mundo das mercadorias" (BENJAMIN, 1989, p. 163). Rosa, como fez Baudelaire, empreende o fazer poético na cidade, humanizando a mercadoria, poetizando a propaganda. Benjamin expõe:

O empreendimento de Baudelaire foi o de trazer à luz, na mercadoria, a aura que lhe é própria. Procurou, de uma maneira heroica, humanizar a mercadoria. Esse intento tem sua contrapartida na tentativa burguesa simultânea de humanizar a mercadoria de uma maneira sentimental: dar à mercadoria, como ao homem, uma casa. (BENJAMIN, 1989, p.163).

Vemos, pois, que a metáfora "le / rouge baiser / permet / le baiser..." (DDEP, p. 119), coloca-se na transferência de um discurso para outro, não apenas do nível da palavra, como define Aristóteles: “A metáfora é a transferência de uma palavra que pertence a outra coisa, ou do gênero para a espécie ou da espécie para o gênero ou de uma espécie para outra por analogia." (POÉTICA, 1457 b). Ametáfora em DDEP, "brota" do pragmático para "desembocar" em imagens poéticas. Paul Ricœur argumenta em La Métaphore Vive: "Tous les autres usages (mots rares, néologismes, etc) dont la métaphore se rapproche sont donc eux aussi des écarts par rapport à l'usage ordinaire." (RICOEUR, 1975, p. 26). Para tanto, a escrita do diário dá-se em reflexão, na necessidade de "estar sozinho a bordo", para que as metáforas se alonguem em possibilidades novas, para que sejam depois divulgadas ao público, em "inteira cinza" e "Oceano":

Redigir honesto um diário seria como deixar de chupar no quente cigarro, a fim de poder recolher-lhe inteira a cinza.

O diário tem dois titulos: às vezes é "Nautikon", às vezes "Sozinho a bordo". Sozinho de verdade, não. Apenas, cada um de nós traz sua parte chão e uma outra oceano?

2-X-As sete sereias do longe: si mesmo, o céu, a felicidade, a aventura, o longo atalho chamado poesia, a esperança vendada e a saudade sem objeto. (DDEP, p.120).

\section{CRIAÇÃO E RECRIAÇÃO: DIPLOMACIA EM DDEP E DDEP-III:}

Em DDEP e DDEP-III, a língua francesa entra no processo de

9 O grifo é nosso. 
criação/recriação por meio da experimentação, a qual em Guimarães Rosa, faz-se em destaque por meio dos neologismos, marca de criação do autor mineiro: "Desentendo; espero. E ela parola, parla, lala10, guegreja, greciza, verso ou prosa, sem pausa." (DDEP, p. 120). E ainda: "28-VIII-4911- Vim até ao fim da Linha 9 do metrô, à Mairie de Montreuil: Montreuil, Montrerel ou Monsterol, Monasteriolum." (DDEP-III, p. 336). Como é possível perceber, no primeiro trecho de DDEP, Rosa elabora a recriação a partir do italiano, criação" ${ }^{12}$ realizada a partir do verbo "parlare", em terceira pessoa do singular, "parla", recriando em "lala". Na sequência, temos um exemplo exímio de diplomacia entre línguas, como em "gregreja" e "greciza", palavras de origem grega, fazendo-se referência à mulher ${ }^{13}$ que se apresenta ao autor, uma grega. Tal procedimento em Rosa, perpassa no plano da transculturação. Segundo Fantini: "A agência transculturadora caracteriza-se pela imediação entre diferentes instâncias culturais discursivas." (FANTINI, 2008, p. 86).

Em DDEP-III, temos o francês no interior do processo de re(criação) e valoração de seu desenvolvimento como vocábulo, no qual o autor "brinca" em possibilidades, latinizando-a: "Montreuil, Montrerel ou Monsterol, Monasteriolum." (DDEP-III, p. 336). Rosa explica no Prefácio "Hipotrélico", de Tutaméia: "À neologia, emprego de palavras novas, chamava Cícero 'verborum insolentia'. Originariamente, insolentia designaria apenas: singularidade, coisa ou atitude desacostumada, insólita; mas, como a novidade sempre agride, daí sua evolução semântica.” (ROSA, 2017, p. 94). Assim, os sistemas linguísticos nos diários, afirmam o caráter da convivência com o outro, como sublinha Marli Fantini em Guimarães Rosa: Fronteiras, Margens, Passagens: "A opção em conviver com diferentes sistemas culturais e linguísticos é endossada por esta afirmativa do narrador de Grande Sertão: Veredas: 'Toda a vida gostei demais de estrangeiros' (GSV, 107)." (FANTINI, 2008, p.88). Fantini comenta o gosto do personagem Riobaldo nos valores estrangeiros, o qual poderia servir de parâmetro no caso de DDEP e DDEPIII, já que estamos em análise de línguas que se intercruzam no discurso do diário, numa pluralidade de culturas e formações. Ainda de acordo com Fantini: "a passagem de uma cultura à outra pode resultar em ganhos sem implicar necessariamente a perda prévia de componentes ou usos culturais." (FANTINI, 2008, p. 86). Dessa forma, entendemos os trechos do diário, como possível locus de enunciação, de trocas simbólicas por sistemas linguísticos distintos.

\section{LÍNGUA FRANCESA EM "POEMA DE CIRCUNSTÂNCIA":}

10 O grifo é nosso.

11 Indicativo de dia, mês e ano, respectivamente.

12 Cf. Lima, 1969, p. 75: "Constatamos, por conseguinte, que já ao nível da linguagem a invenção vocabular não é um artifício ou um luxo desnecessário, mas necessitada pela própria maneira escolhida de focar a sua matéria."

13 Cf. DDEP, p.119: “Apresentaramme a uma moça grega, que veio a Paris estudar cinema. Moça, digo, pela idade aparente. Porque é casada. Senhora Kórax, ou Hiérax, ou Skolópax; só sei que um nome de ave. Porém seu prenome é Ieoana."

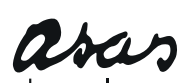

da palavra

VOL. 15 | N.2 | DEZ.2018 ISSN 1415-7950
Ao final de DDEP, o diplomata escritor insere um "Poema de Circunstância", escrito em língua francesa, desenvolvido, ao que indica no andamento do diário, do contato com a mulher grega: "Almoço com Ieoana, no 'La Rotonde', onde há comida basca e orquestra magiar" (DDEP, p. 121). O "Poema de Circunstância", "brota", como o título indica, do cotidiano, das circunstâncias do contato. Ei-lo na íntegra:

\section{Poema de Circunstância}

Je m'en vais de Hellas

Mon bonheur aussi.

Nous nous en allons d'emblée

nous quittons l'Olympe aux nuages

de marécage et d'étain.

Mon bonheur, eh bien

on s'en va d'ici. 


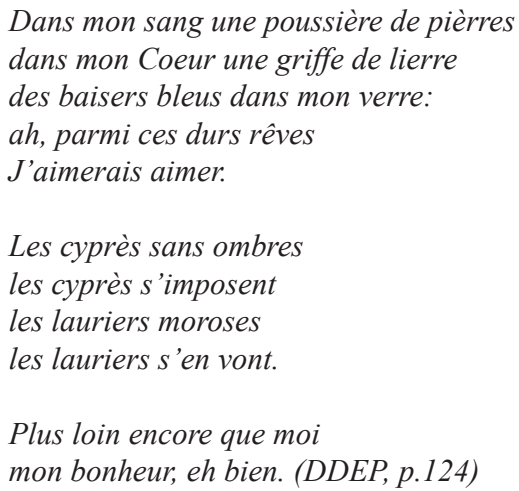

No que tange ao conteúdo do poema, comojádissemos, a circunstância encontra-se no centro da poiesis, constituindo-se como um "grand finale" de todo o diário, principalmente dos encontros proporcionados, indicadas em anotações, bem como o pensar ou estar "sozinho a bordo". Na primeira estrofe, a voz poética declara a saída de "Hellas", fazendo-se referência à Grécia, levando-se sua felicidade embora também. É importante ressaltar, que o texto pretende-se como um comentário de todo o diário. Sendo assim, devemos abordá-lo na conjuntura diária dos acontecimentos, como o título revela, são circunstanciais.

Na segunda estrofe, deixa-se o Olimpo, a montanha mais alta, morada de cristal dos deuses, para atingir e inserir-se nas "nuages de marécage et d'étain", um lugar menos importante, considerando a escala de valor, mas que é a própria realidade, a felicidade em situação não confirmada, nunca atingida e plena: "mon bonheur, eh bien / on s'en va d'ici.". A instabilidade da felicidade faz parte da temática roseana, colocada em evidência em diversos personagens de sua obra, como é o caso de Grande sertão: veredas. É o estado de ambivalência em que o homem sempre se encontra, questões recorrentes no sertão ficcional de Rosa. Luiz Costa Lima argumenta em Por que Literatura: "Em Guimarães Rosa o homem e a terra não são isto ou aquilo. São conjuntamente isso e aquilo, loucura e saúde, medo e coragem. Ambivalência. (LIMA, 1969, p.74). A felicidade no "Poema de Circunstância" existe no jogo da meditação, uma espécie de "camada do ser", como propõe o próprio Rosa no Prefácio "Sobre a escova e a dúvida", de Tutaméia:

É o que mais se parece com a felicidade: um modo sem sequência, desprendido dos acontecimentos- camada do nosso ser, por ora oculta-fora dos duros limites do desejo e de razões horológicas. Não se imagina o perigo que ainda seria, algum dia, em alguma parte, aparecer uma coisa deveras adequada e perfeita. (ROSA, 2017, p.183).

E ainda:

\begin{abstract}
A felicidade não se caça. Pares amorosos voltam às vezes a dado lugar, querendo reproduzir êxtases ou enlevos; encontram é desrequentado, discórdia e arrufo, aquele caminho não ia dar a Roma nenhuma. Outros recebem o dom em momentos neutros, até no meio dos sofrimentos, há as doses pausas de angústia. (ROSA, 2017, p.184).
\end{abstract}

Em relação à terceira estrofe, consideramos ser o "ponto alto" do poema, construída em belas metáforas: "Dans mon sang une poussière de pièrres / dans mon Coeur une griffe de lierre". A voz ficcional emaranha-se em imagens contraditórias, da fluidez do sangue e compacto do pó das pedras, metáfora enigmática e interessante, porque flui do estranhamento, como desenvolve Aristóteles, ao considerar aquilo que deve ser uma excelente 
figura retórica: "É com efeito, a partir de bons enigmas que se constituem geralmente metáforas apropriadas. Ora, metáforas implicam enigmas e, por conseguinte, é evidente que são métodos de transposição." (RETÓRICA, III, 2, 1405 b). Enumeremos outras metáforas de DDEP-III: "Também os defeitos dos outros são horríveis espelhos. / Os Santos foram homens que alguma vez acordaram e andaram os desertos de gelo. / Somos cegos transparentes. / Saudade é ser, depois de ter." (DDEP-III, p.337-338).

Ainda na terceira estrofe, temos aquilo que parece ser o mote do poema: "J'aimerais aimer", constituindo-se, pois, como um desejo, uma vontade ligada ao eu que se coloca em situação de "durs rêves". Amar realizase na dificuldade, na idealização das partes, num estágio difícil, ideal, isto é, um platonismo do mundo das ideias, talvez explicativo para o comentário de Ieoana, a mulher grega, ao final do poema: "_Ah, mon ami, vous êtes platonicien!" (DDEP-III, p.124). Nas duas últimas estrofes, temos outras bem elaboradas metáforas, agora com os "cyprès", vegetação cultivada desde a antiguidade e que são típicas do mediterrâneo oriental. No "Poema de Circunstância", os ciprestes, assim como o coração e o sonho, constituem-se em etapas de personificação, cujos sentimentos alargam-se no eu do poema, sendo tristes e necessários, como na imagem "les lauriers moroses". Todos os sentimentos e impressões são circunstâncias e reflexões sob a paisagem: "Sim, é na ponte Neuf que o Sena é mais belo. Mas onde gosto mais dele é na Pontau-Change." (DDEP-III, p.124).

\section{CONSIDERAÇÕES FINAIS}

A Língua Francesa em Do Diário em Paris e Do Diário em Paris-III, elabora-se no cotidiano da escrita do diário, reflexões que nascem do dia a dia do autor mineiro, seja refletindo a paisagem ou na conversa diária, um "rendez-vous" pela cidade parisiense, cujos encontros são "abastecedores" de imagens que convergem no poético. Paris e a língua, então, é o corpus da poiésis, fazendo-se como uma espécie de privilegiado "lieu" para o autor/ diplomata. A cidade ao olhar do poeta emerge da poesia, encontrando-se em anúncios, pontes e estações. Paris é desenhada pelo artista, que a imagina em imagens e cores: "Para o escritor, também, de primeiro podia haver disso, nos pincéis: preto como azeviche ou a noite e fuligem, branco como alabastro ou a neve, vermelho como o fogo, rubis, amarelo açafrão, azul-céu. Hoje, porém, é azul ou verde ou vermelho, só, sem mais." (DDEP, p.118). A língua Francesa em ambos os diários, coloca-se à disposição do "olhar atento" de Rosa, lugar que emana de pequenas situações da vida e experiências linguísticas do outro.

\section{REFERÊNCIAS:}

ARISTÓTELES. Retórica. Tradução de Manuel Alexandre Júnior, Paulo Farmhouse Alberto e Abel do Nascimento Pena. São Paulo: Martins Fontes, 2012.

Gulbenkian, 2008.

Poética. Tradução de Ana Maria Valente. Lisboa: Calouste

BENJAMIN, Walter. Paris, capital do século XIX. Tradução de Maria Cecilia Londres. In: Teoria da literatura em suas fontes. Organização, Seleção e Introdução de Luiz Costa Lima. 3 a edição. Rio de Janeiro: Civilização Brasileira, 2002, pp. 689-706.

Charles Baudelaire: um lírico no auge do capitalismo. Tradução de José Carlos Martins Barbosa e Hemerson Alves Baptista. 1ª ed. São Paulo: Brasiliense, 1989. 3 v. 
Editora, 2013.

FANTINI, Marli. Guimarães Rosa. Fronteiras, Margens, Passagens. 2a edição. São Paulo: Ateliê Editorial, 2008.

LIMA, Luiz Costa. Por que literatura. Petrópolis: Vozes, 1969.

ROSA, João Guimarães. Ave, Palavra. $6^{\text {a }}$ edição. Rio de Janeiro: Nova Fronteira, 2009.

. Tutameia (Terceiras Estórias). $10^{\mathrm{a}}$ edição. Rio de Janeiro: Editora Nova Fronteira, 2017.

RICOEUR, Paul. La métaphore vive. Paris: Éditions du Seuil, 1975.

\section{Recebido em 02 Out 2018 ～Aprovado em 21 Out 2018}

Fabrício Lemos da COSTA

Graduado e Licenciado em Letras-Língua Portuguesa pela UFPA-PA, Especialista em Produção de Material Didático e Formação de Leitores para a EJA pela UNIFAP-AP, Graduando em Filosofia pela UEAP-AP. E-mail: fabricio.lemos1987@yahoo.com.br.

Sílvio Augusto de Oliveira HOLANDA

Possui graduação em Letras (Português/Francês) pela Universidade Federal do Pará (1990), mestrado em Letras/Teoria Literária pela Universidade Federal do Pará (1994), doutorado em Letras (Teoria Literária e Literatura Comparada) pela Universidade de São Paulo (2000) e pós-doutorado em Estudos Românicos pela Universidade de Lisboa (2007). E-mail: eellip@hotmail.com. 